\title{
MORPHOLOGY AND INVOLUTION OF HUMAN ADRENAL GLAND DURING FOETAL LIFE
}

\author{
Manju Madhavan $C^{1}$, Susan Varghese ${ }^{2}$ \\ ${ }^{1}$ Associate Professor, Department of Anatomy, Government Medical College, Thiruvananthapuram. \\ ${ }^{2}$ Associate Professor, Department of Anatomy, Government Medical College, Thiruvananthapuram.
}

\begin{abstract}
BACKGROUND

Foetal adrenal glands play a vital role in the maturation of all organs and in the maintenance of pregnancy. Ultrasonological examination of adrenal glands during foetal life gains importance as a valuable tool to predict preterm labour and neonatal survival. Thus, knowledge about its normal morphological parameters becomes necessary. This study deals with gross and histological features of normal foetal adrenal gland at various gestational ages in detail.
\end{abstract}

\section{MATERIALS AND METHODS}

Adrenal glands were dissected out from 33 normal stillborn human foetuses. Size and weight of the adrenal glands were measured and correlated with gestational age and birth weight. Structure of adrenal cortex, width of the permanent zone and foetal zone in relation to the total width of the cortex, morphological features of the cells in the two zones, features suggestive of involution and distribution of chromaffin tissue were studied by microscopy. Mean values for different parameters were calculated and relationships between them were assessed.

\section{RESULTS}

The size and weight of the glands were found to be increasing progressively with increase in the gestational age. Adrenal weight as a percentage of birth weight showed maximum values around 20 weeks of gestational age. Accessory nodules were seen microscopically in the capsule which fused later with the cortex. Percentage of the permanent zone was 10-20\% at all gestational ages. The cytoplasm of foetal zone cells was PAS positive and rich in mitochondria. Features suggestive of involution were noted from 28 weeks of gestational age. Chromaffin tissue was seen as nodules in the periphery of the gland in early gestational ages. It migrated to the central part to be concentrated around the central vein later on.

\section{CONCLUSION}

Morphological features of adrenal gland correlated well with the corresponding gestational age and also its function. Involution of the gland started from 28 weeks of gestational age.

\section{KEYWORDS}

Foetal Adrenal Gland, Permanent Zone, Foetal Zone, Involution, Chromaffin Tissue.

HOW TO CITE THIS ARTICLE: Madhavan MC, Varghese S. Morphology and involution of human adrenal gland during foetal life. J. Evolution Med. Dent. Sci. 2016;5(80):5989-5994, DOI: 10.14260/jemds/2016/1352

\section{BACKGROUND}

Adrenal glands of foetuses are relatively large structures and are made up of a fairly firm yellowish grey cortex and a broad brownish red inner medulla. It can be demonstrated microscopically in seven to eight mm embryos. By 20 weeks, the glands become as large as kidneys and by 30 weeks achieve a size 10-20 fold as that of adult glands. ${ }^{1}$ An increase in rate of growth of the gland is directly correlated with rapid maturation of different organ systems. ${ }^{2}$ In recent studies, the gross measurements of the adrenal glands have evolved as an important factor because these data help in measuring and interpreting the gland size in ultrasonological examinations.

Financial or Other, Competing Interest: None.

Submission 28-08-2016, Peer Review 22-09-2016,

Acceptance 28-09-2016, Published 06-10-2016.

Corresponding Author:

Dr. Manju Madhavan C

Kadukkara Veedu,

T. C. 13/1900(7), Koyikkal Lane,

Kumarapuram,

Medical College (P. O.)

Thiruvananthapuram-695011.

E-mail: manjumadhavanmch@gmail.com

DOI: $10.14260 /$ jemds/2016/1352
Microscopic structure of foetal adrenal cortex differs significantly from its adult counterpart with the presence of a foetal zone which completely involutes in postnatal life. The microscopic features of permanent and foetal zonal cells differ from each other throughout gestation. The functions attributed to them are also different. Permanent zone develops into adult adrenal cortex after birth. But the foetal zone is the one which is active during foetal life and produces steroid hormones. Its development is under the influence of many tropic factors like ACTH, Basic fibroblast growth factor, transforming growth factor $\beta /$ epidermal growth factor, Insulin-like growth factor (IGF-1 \& 2), corticotrophin, oestrogen, etc. ${ }^{3}$ Decreased width or cytomegaly affecting this zone presents in neonatal life as adrenal hypoplasia and adversely affects neonatal survival. ${ }^{4}$

The future adrenal medulla is represented in the foetal adrenal gland as groups of neuroblastic (Chromaffin) tissue. Full development of adrenal medulla is not achieved in-utero. The major development is during first three years of postnatal life.

By this study, we hope to provide a better understanding of morphological features of the foetal adrenal gland and set standards for different parameters at various gestational stages of the foetus. 


\section{AIMS AND OBJECTIVES}

To study the gross and microscopic structure of human foetal adrenal gland at different gestational ages, to correlate the morphology of foetal adrenal gland with its function, and to study the development and growth of adrenal cortex and medulla during foetal life.

\section{MATERIALS AND METHODS}

Thirty three human foetuses autopsied in the Department of Pathology were used for this study. Their gestational ages ranged from 12-40 weeks (Table 1). Foetuses with congenital anomalies and of mothers having history of diabetes or hypertension were excluded from the study.

\begin{tabular}{|c|c|c|}
\hline Sl. No. & Age Group (Weeks) & No. of Foetuses \\
\hline 1 & $12-16$ & 4 \\
\hline 2 & $17-20$ & 6 \\
\hline 3 & $21-24$ & 4 \\
\hline 4 & $25-28$ & 9 \\
\hline 5 & $29-32$ & 5 \\
\hline 6 & $33-36$ & 1 \\
\hline 7 & $37-40$ & 4 \\
\hline Total & Table 1 \\
\hline \multicolumn{3}{|c|}{} \\
\hline
\end{tabular}

Birth weights of the foetuses were noted. The adrenal glands were dissected out on each side. Weight, maximum vertical height (L1), maximum width (L2) and maximum thickness (L3) of the glands were measured.

Weights were measured using electronic weighing machine and lengths were taken using divider and measuring scale.

Combined adrenal weights were calculated by adding adrenal weights of either side in each case and were expressed as a percentage of body weight. Combined size of the adrenal glands were calculated by multiplying L1, L2 and L3 of each side and then adding the resultant values together.
The adrenals were then transported to Department of Anatomy in $10 \%$ formalin, fixed, sectioned and stained by haematoxylin and eosin. The sections were observed under low power objective to study the capsule, morphology of cells in cortex, presence of features of involution and distribution of chromaffin tissue in the gland. The total width of the cortex, width of permanent zone and width of foetal zone were taken using a horizontal eyepiece micrometre called graticule. The graticule was calibrated with a stage micrometre. A stage micrometre is a glass slide of three inches in length with a scale engraved on it. The scale is one millimetre long and is divided into 0.1 and 0.01 parts of a millimetre. The value of one eyepiece division is determined by calibrating with stage micrometre for every optical combination to be used. ${ }^{5}$

Width of permanent zone as a percentage of total width of the cortex was calculated at five different sites in a selected section of the gland. Then, the average values were calculated.

Changes of involution in the glands were graded according to the method described by Bech et al (1969) ${ }^{6}$ by observing necrosis, haemorrhage, and vacuolation in the section under high power objective. He defined haemorrhage, necrosis and vacuolation as follows.

\section{Haemorrhage}

Isolated single cells completely surrounded by red blood cells.

\section{Necrosis}

Swollen cells with light fragmented cytoplasm and pale or indistinct nuclei, or shrunken cells with acidophilic cytoplasm and pyknotic nuclei (More than $25 \%$ cells in a field magnified 400 times should be necrotic to name that region necrotic).

\section{Vacuolation}

Clear spaces intracellularly or around cells. Grading was done as detailed in table 2 as described by Bech et al. ${ }^{6}$

\begin{tabular}{|c|c|c|c|c|}
\hline Features & Grade 1 & Grade 2 & Grade 3 & Grade 4 \\
\hline Haemorrhage & Absent & $\begin{array}{c}\text { Only in the central } \\
\text { part of foetal zone }\end{array}$ & $\begin{array}{c}\text { In entire } \\
\text { foetal zone }\end{array}$ & $\begin{array}{c}\text { In both zones } \\
\text { of cortex }\end{array}$ \\
\hline Necrosis & Absent & $\begin{array}{c}\text { In central } \\
\text { and some } \\
\text { part of foetal zone } \\
\text { localised regions of } \\
\text { peripheral foetal zone }\end{array}$ & $\begin{array}{c}\text { In entire } \\
\text { foetal zone }\end{array}$ \\
\hline Vacuolation & Absent & $\begin{array}{l}\text { Only in the central } \\
\text { part of foetal zone }\end{array}$ & $\begin{array}{c}\text { In central } \\
\text { and some } \\
\text { localised regions of } \\
\text { peripheral foetal zone }\end{array}$ & $\begin{array}{c}\text { In entire } \\
\text { foetal zone }\end{array}$ \\
\hline
\end{tabular}

Grade of involution was calculated by adding the grades of haemorrhage, necrosis and vacuolation.

The sections were observed under oil immersion objective to study the characteristics of different types of cells. Size of the cells and nuclei were measured with graticule. The sections were stained using PAS stain to study the secretory activity and modified Masson's trichrome stain for visualising mitochondria.
Foetuses were grouped into 7 groups as shown in Table 1. Mean values of all parameters in each group were calculated to summarise the data.

\section{RESULTS}

Mean values and standard deviation of the different parameters in each gestational age group are shown in Table 3. 


\begin{tabular}{|c|c|c|c|c|c|c|c|c|c|c|}
\hline \multirow{2}{*}{$\begin{array}{c}\text { Gestational } \\
\text { Age }\end{array}$} & \multicolumn{2}{|c|}{$\begin{array}{c}\text { Birth } \\
\text { Weight (g) }\end{array}$} & \multicolumn{2}{|c|}{$\begin{array}{c}\text { Combined Adrenal } \\
\text { Weight (g) }\end{array}$} & \multicolumn{2}{|c|}{$\begin{array}{l}\text { Combined Size of the } \\
\text { Adrenal Glands }\left(\mathrm{cm}^{3}\right)\end{array}$} & \multicolumn{2}{|c|}{$\begin{array}{c}\text { Combined Adrenal Weight as } \\
\% \text { of Birth Weight }\end{array}$} & \multicolumn{2}{|c|}{$\begin{array}{l}\text { Percentage of } \\
\text { Permanent Zone }\end{array}$} \\
\hline & Mean & SD & Mean & SD & Mean & SD & Mean & SD & Mean & SD \\
\hline $12-16$ & 161.95 & 83.99 & 0.48 & 0.25 & 1 & 0.54 & 0.285 & 0.03 & 16.75 & 2.75 \\
\hline $17-20$ & 247.17 & 97.38 & 0.87 & 0.39 & 1.7 & 0.72 & 0.355 & 0.07 & 14 & 2.09 \\
\hline $21-24$ & 556.5 & 122.55 & 2.23 & 0.39 & 4.2 & 0.63 & 0.407 & 0.06 & 12.25 & 2.87 \\
\hline $25-28$ & 724.56 & 246.60 & 2.16 & 0.79 & 4.2 & 1.58 & 0.301 & 0.04 & 13.67 & 3.2 \\
\hline $29-32$ & 959.8 & 371.99 & 3.04 & 1.31 & 6.16 & 2.8 & 0.311 & 0.03 & 14 & 2.54 \\
\hline $33-36$ & 2400.00 & 0 & 7.4 & 0 & 15 & 0 & 0.308 & 0 & 14 & 0 \\
\hline $37-40$ & 2800 & 230.94 & 8.45 & 1.04 & 16.7 & 1.95 & 0.304 & 0.06 & 14.25 & 2.21 \\
\hline \multicolumn{11}{|c|}{ Table 3: Mean Values and Standard deviations (SD) of the different Parameters } \\
\hline
\end{tabular}

Size of the glands were slightly higher on the left side. Combined size of the glands increased progressively as the gestational age increased. It attained the same size of the kidney during 16 th week of gestation. Then, its relative size gradually decreased and it became one-third the size of the kidney at fullterm.

The weight of the adrenal gland increased progressively as the gestational age advanced (Graph 1). Adrenal weight as a percentage of birth weight showed highest values around 20th week of gestational age (Table 3). Left side glands were heavier than the right ones.

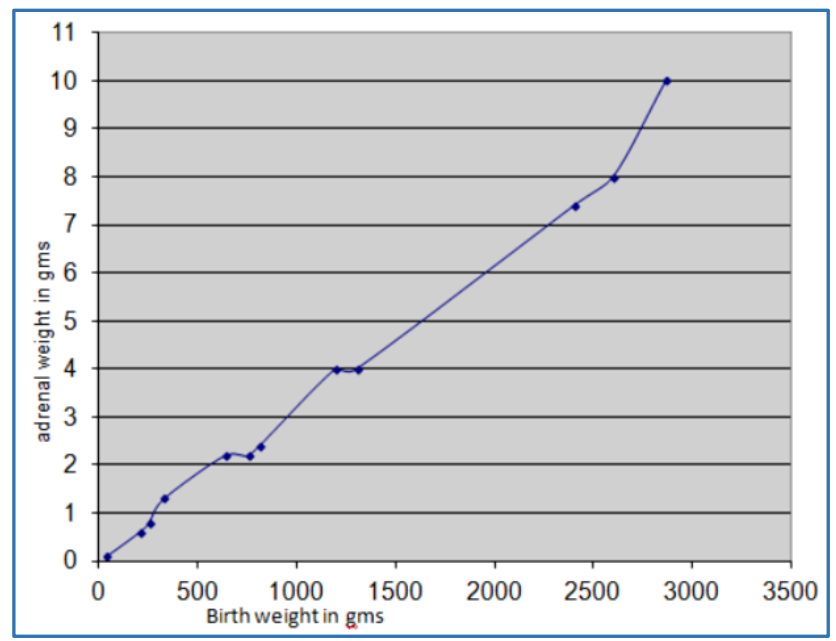

Graph 1: The Relationship of Adrenal Weight and Birth Weight

Microscopically, the whole adrenal gland was covered by a well-defined capsule. The capsule was made up of connective tissue, with cells and fibres, and numerous blood vessels.

The cells of the capsule were elongated with central oval nuclei. Extensions of the capsule into the parenchyma could be made out.

Adrenal cortex was seen just beneath the capsule with an outer narrower permanent zone and inner wider foetal zone (Figure 1). The permanent zone formed only about 10 to $20 \%$ of the total cortical thickness in all gestational ages (Table 3).

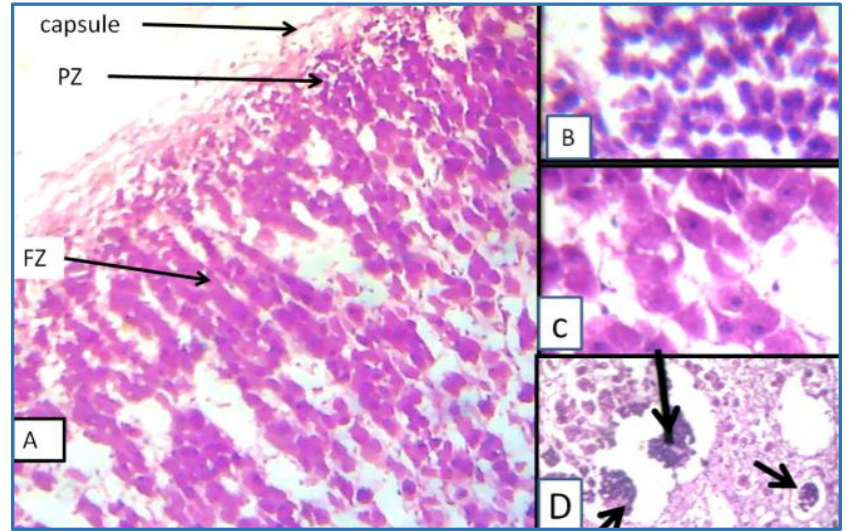

Fig. 1: A- Foetal adrenal gland at 26 weeks gestation under low power objective (PZ-permanent zone, FZ-foetal zone). $B$-Permanent zone under high power objective. $C$ - Foetal zone under high power objective. D-Groups of neuroblastic (chromaffin) cells under low power objective.

Permanent zone was made up of closely packed small round or oval cells with average diameter of 7 to 8 microns. The cells were arranged as small round or oval groups separated by clear spaces. Towards inner aspects, the cells were arranged as short columns. Cytoplasm was slightly basophilic and formed a thin rim around the nucleus. The nucleus was darkly stained with an average diameter of 5 to 6 microns (Figure 1B). But in some cells, the nuclei showed a vesicular appearance with aggregation of chromatin towards the nuclear membrane. 1 or 2 nucleoli could also be identified in these cells.

Foetal zone is the wide inner zone of the foetal adrenal cortex. It contained large polyhedral brightly eosinophilic cells arranged as fasciculi of 2 to 3 cell thickness. Towards the inner aspects, the cells were having a reticular arrangement and were loosely packed (Figure 1A). Average diameter of the cells ranged from 13 to 24 microns. They contained central oval nuclei with a diameter of 5 to 6 microns (Figure 1C). Nuclei were pale and usually showed clumping of chromatin towards the nuclear membrane and prominent nucleoli. Two types of cells were identified- light and dark. The cytoplasm of the dark cells was more darkly eosinophilic and granular when compared with that of light cells. Dark cells were seen more towards the periphery of the foetal zone. 
Large numbers of mitochondria within the foetal zone cells were demonstrated by Masson's trichrome stain (Figure 2). Secretory material within the cells was demonstrated by Periodic acid Schiff reaction (Figure 3). The dark cells were more PAS positive than the light cells (Figure 3).

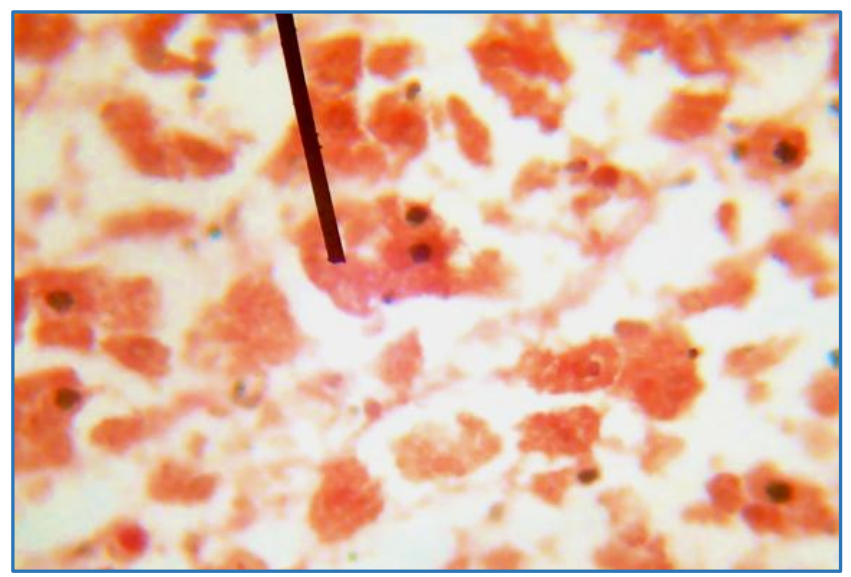

Fig. 2: Adrenal gland in a 24-week-old normal female foetus, Masson's trichrome stain $\times$ 400, showing increased amount of mitochondria (as red granules) within the cytoplasm of foetal zone cells

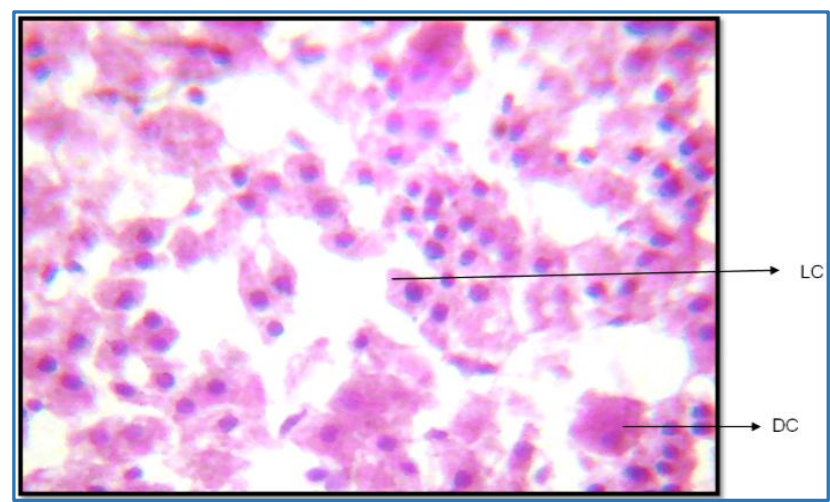

Fig. 3: Adrenal gland in a 20-week-old normal male foetus, $P A S$ staining $\times$ 400. Dark cells (DC) and light cells (LC) can be differentiated well

Accessory nodules of cortex were present within the capsule after 18 weeks of gestation. Some of them had only connective tissue cells, some had permanent zone whereas others had both permanent and foetal zones. They were seen to be fusing with the main gland (Figure 4).

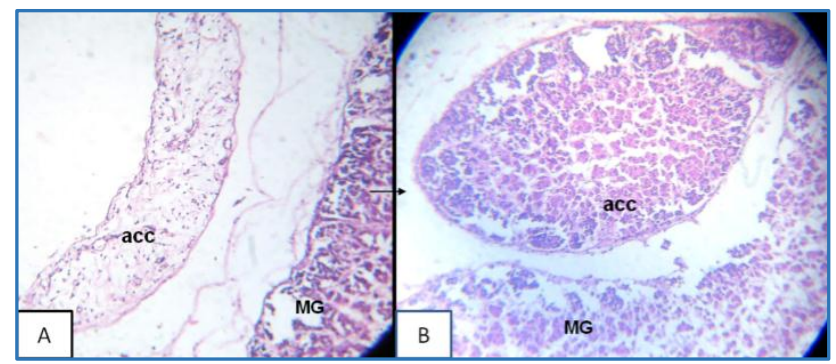

Fig. 4: Stages of development of accessory nodules Acomposed of connective tissue cells. B-composed of permanent zone and foetal zone resembling the main gland, acc-accessory nodule, MG-main gland
Vacuolation was noted both intra and extracellularly within the foetal zone in late second trimester and third trimester. Haemorrhages were also present in some specimens irrespective of gestational age. Necrosis of the foetal zone cells was noted from 28 weeks onwards (Figure 5). Cell size in foetal zone became lesser as gestational age advanced. The grading of haemorrhage, necrosis and vacuolation were done as described by Bech. ${ }^{6}$

Grade of involution was calculated by adding the grade of haemorrhage, necrosis and vacuolation. This was correlated with size of cells in permanent and foetal zones (Table 4). No significant correlation was observed between degrees of involution and size of cells in permanent zone, while a significant negative correlation was observed between them in foetal zone.

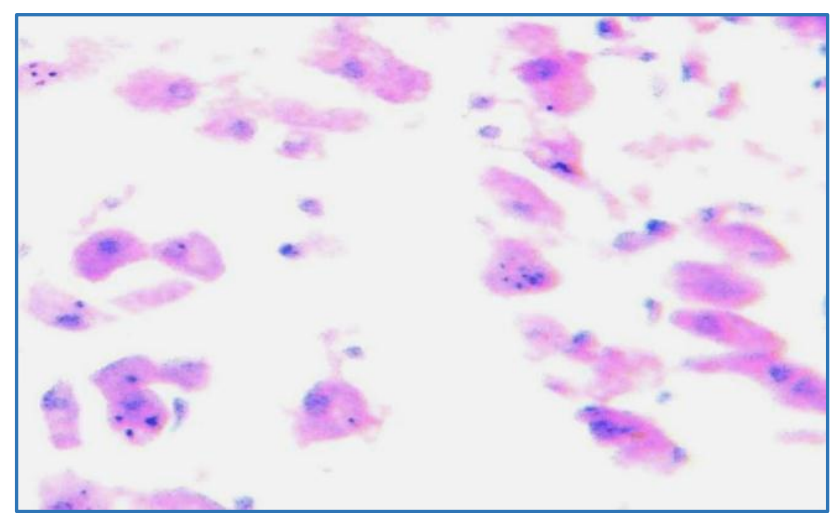

Fig. 5: Adrenal gland in a 32-week-old male foetus under high power objective. Foetal zone showing feature of involution

\begin{tabular}{|c|c|c|c|}
\hline $\begin{array}{c}\text { Gestational } \\
\text { Age } \\
\text { (Weeks) }\end{array}$ & $\begin{array}{c}\text { Grade } \\
\text { of } \\
\text { Involution }\end{array}$ & $\begin{array}{c}\text { Cell size in } \\
\text { Foetal } \\
\text { Zone } \\
\text { (Microns) }\end{array}$ & $\begin{array}{c}\text { Cell Size in } \\
\text { Permanent } \\
\text { Zone } \\
\text { (Microns) }\end{array}$ \\
\hline $12-16$ & 4 & 18 & 8 \\
\hline $17-20$ & 5 & 17 & 7 \\
\hline $21-24$ & 6 & 16 & 7 \\
\hline $25-28$ & 6 & 16 & 7 \\
\hline $29-32$ & 7 & 14 & 7 \\
\hline $33-36$ & 7 & 14 & 8 \\
\hline $37-40$ & 8 & 14 & 7 \\
\hline \multicolumn{4}{|c|}{ Table 4: Relationship of Grade of } \\
Involution, Gestational age and Cell Size \\
\hline \multicolumn{4}{|c}{} \\
\hline
\end{tabular}

Numerous blood vessels were also seen in the foetal zone. A large central vein could be identified towards the centre of the gland.

Chromaffin tissue could be identified within the adrenal gland from 12 weeks onwards. They appeared as cell nests within the cortex characterised by collections of densely packed small cells with overlapping nuclei (Figure 1D). The cytoplasm was basophilic and the nuclei were intensely staining. They were arranged around the central vein in the late second and the third trimester.

\section{DISCUSSION}

The developing human adrenals have attracted the attention of numerous researchers due to its vital nature, unique structure and controversial developmental origin. The various 
findings obtained in this study are discussed here in comparison with previous works.

In previous studies conducted by Gaillard et al (1990) 7 and Anand et al (1998), 8 the combined adrenal size correlated well with gestational age and birth weight. Similar findings were observed in the present study.

The weight of the gland increases as the gestational age and birth weight goes up. The adrenal weights at different gestational ages as per this study agree well with the results of Rakh Rajendra S et al. ${ }^{9}$ The graph (Graph 1) obtained by plotting the weights of the glands in Y-axis and birth weights in X-axis closely resembles that presented in previous studies of Jackson (1909), Spector (1956) and Kondo (1959) as cited by Buster. ${ }^{2}$ There is a rapid increase in growth velocity of the gland during 32 and 36 weeks, which coincides with the acceleration of foetal maturation before delivery. But adrenal weight as a percentage of birth weight was maximum during four to five months of gestational age. Same findings were observed earlier.6,10,11 It may be due to its role in the development of other organs during this period.

The microscopic picture of foetal adrenal gland presents two well-differentiated cortical zones - an outer narrow permanent zone and inner wider foetal zone. Medulla is not well formed and it is represented by nests of neuroblastic cells which migrate from periphery to central part of the gland. Similar appearance is described by previous workers. ${ }^{1,12}$

Accessory nodules of cortical tissue were noted within the capsule in almost all the glands after eighteen weeks. In some sections, they were seen to be fusing with the main tissue as to increase the gland size. Usually they were composed of cells similar to permanent zone. But in some sections they contained both foetal and permanent zone elements. In some glands, nodules were composed of cells resembling connective tissue cells. This shows that the cortical cells of the gland are derived from cells of the capsule. This finding supports the view of cytogenesis of cortical cells from mesenchyme by Greunwald. ${ }^{13}$ This is against the opinion of Hett $^{14}$ who described accessory nodules as the detached parts of the main gland.

The cystic spaces within the permanent zone were also noted from the early second trimester as reported in previous works.15,14,16 The spaces were predominantly towards the capsule. But presence of these spaces could not be considered as an abnormality because in this study, they were noted in almost all the glands irrespective of grade of involution or presence of any other features suggestive of intra-uterine stress. The spaces narrowed to form slits in the adrenals of full term foetuses in agreement with the work of Benner. ${ }^{16}$ The present study agrees with the postulate of Hett ${ }^{14}$ and Keen and Hewer ${ }^{1}$ that the arrangement of cells around the cystic spaces represents the remodeling of permanent zone to produce zona glomerulosa. This is contradictory to the findings of de Sa ${ }^{17}$ who correlated the presence of cystic spaces with features of intra-uterine stress.

The involution of the foetal zone was noted from 28 weeks onwards. Foetal zone degeneration in the last ten weeks of gestation was noted by other workers.1,6,16 The involution was graded as described by Bech $^{6}$ by grading haemorrhage necrosis and vacuolation. Vacuolation was found to be the first step in involution followed by necrosis. This finding is in conformity with that of Bech ${ }^{6}$. But haemorrhage could not be correlated with involution. Haemorrhage in the foetal zone was absent in many glands with advanced necrosis whereas it was present in many with no necrosis.

Cell size in the foetal zone was seen decreasing with increase in grades of involution. This is contradictory to the findings of Keen and Hewer ${ }^{1}$ who observed increased cell diameters in involuting glands.

Secretory granules could be demonstrated in foetal zone cells by PAS from 14 weeks onwards. Sucheston 18 observed the presence of secretory granules from 16 weeks. Johannison ${ }^{15}$ also demonstrated PAS positive material within the foetal zone cells of second trimester foetuses.

Increased amount of mitochondria was demonstrated by Masson's trichrome stain in the foetal zone. This was also observed by electron microscopic studies. ${ }^{15}$ This suggests that the cells are functionally active.

\section{CONCLUSION}

The present work is a gross and light microscopic study of adrenal glands in human foetuses. This may help to provide a better understanding of the structure of human foetal adrenal gland in relation to its function. The increase in size of the gland is found correlating with foetal maturation. Towards term it starts involuting, thus emphasising its role in the maintenance of pregnancy. Mechanism of growth of the gland is explained by the formation of accessory nodules in the capsule which later differentiates into main gland elements and fuses with the main gland. The different developmental origin of adrenal medulla is shown by the migration of neuroblastic tissue (chromaffin tissue) from the periphery of the gland and their arrangement around the central vein towards the later part of gestation.

\section{REFERENCES}

1. Keene MFL. Observations on the development of the human suprarenal gland. J Anat 1927;61(Pt 3):302-24.

2. Buster JE. Fetal adrenal cortex. Clin Obstet and Gynaecol 1980;23(3):803-24.

3. Langlois D, Li JY, Saez JM. Development and function of human fetal adrenal cortex. J Paed Endocrinol Metab 2002;15(Suppl 5):1311-22.

4. Kerenyi N. Congenital adrenal hypoplasia. Report of a case with extreme adrenal hypoplasia and neurohypophyseal aplasia, drawing attention to certain aspects of etiology and classification. Arch Pathol 1961;71:336-43.

5. Evans WC. Quantitative microscopy. In: Trease and Evan's pharmacognosy. 14th edn. WB Sanders: 1966;576-8.

6. Bech K, Tygstrup I, Nerup J. Involution of the fetal adrenal cortex. A light microscopic study. Acta Pathol Microbiol Scand 1969;76(3):391-400.

7. Gaillard DA, Lallemand AV, Moirot HH, et al. Fetal adrenal development during second trimester of gestation. Paed Pathol 1990;10(3):335-50.

8. Anand MK, Anand C, Choudhry R, et al. Morphology of human suprarenal glands: a parameter for comparison. Surg Radiol Anat 1998;20(5):345-9.

9. Rajendra RS, Sandeep PV, Pramod KR. Morphology of suprarenal gland in human fetuses. International Journal of Recent Trends in Science and Technology 2014;10(1):158-60.

10. Ekholm E, Niemenieva K. On prenatal changes in the relative weights of the human adrenals, the thymus and the thyroid glands. Acta Paed 1950;39(1):67-86. 
11. Ram KS, Sharma M, Sharma A. Morphometric assessment of suprarenal gland in fetuses of different gestational age groups. International Journal of Scientific and Research Publications 2012; 2(12):1-8.

12. Mol MP, Mukherjee A, Shroff G. Histogenesis of suprarenal gland in fetuses of different gestational ages. International Journal of Scientific Research 2014;3(8):265-7.

13. Gruenwald P. Embryonic and postnatal development of adrenal cortex particularly the zona glomerulosa and accessory nodules. Anat Rec 1946;95(4):391-421.

14. Hett J, Beitrag E. Zu histogeneses der menschlichen nebenmere. Z Mikr Anat Forsch 1925;3:179-282.
15. Johannison E. The fetal adrenal cortex in the human. Its ultra-structure at different stages of development and in different functional states. Acta Endocrinol (Copenh) 1968;58( Suppl 130):1-107.

16. Benner MC. Studies on the involution of fetal cortex of the adrenal glands. Am J Pathol 1940;16(6):787-98.

17. de Sa DJ. Adernal changes in chorioamnionitis. Arch Dis Child 1974;49(2):149-51.

18. Sucheston ME, Cannon MS. Microscopic comparison of normal and anencephalic human adrenal gland with emphasis on the transient zone. Obstetrics Gynecology 1970;35(4):544-53. 